\title{
Toughing It Out-Disease-Resistant Potato Mutants Have Enhanced Tuber Skin Defenses
}

\author{
Tamilarasan Thangavel, Robert S. Tegg, and Calum R. Wilson
}

Tasmanian Institute of Agriculture, School of Land and Food, University of Tasmania, New Town Research Laboratories, 13 St John's Avenue, Tasmania 7008, Australia.

Accepted for publication 11 January 2016.

\begin{abstract}
Thangavel, T., Tegg, R. S., and Wilson, C. R. 2016. Toughing it out-Disease-resistant potato mutants have enhanced tuber skin defenses. Phytopathology 106:474-483.

Common scab, a globally important potato disease, is caused by infection of tubers with pathogenic Streptomyces spp. Previously, diseaseresistant potato somaclones were obtained through cell selections against the pathogen's toxin, known to be essential for disease. Further testing revealed that these clones had broad-spectrum resistance to diverse tuber-invading pathogens, and that resistance was restricted to tuber tissues. The mechanism of enhanced disease resistance was not known. Tuber periderm tissues from disease-resistant clones and their susceptible

suberin biosynthesis and innate defense pathways within these tissues were also examined. The disease-resistant somaclones reacted to both pathogen and toxin by producing more phellem cell layers in the tuber periderm, and accumulating greater suberin polyphenols in these tissues. Furthermore, they had greater expression of genes associated with suberin biosynthesis. In contrast, signaling genes associated with innate defense responses were not differentially expressed between resistant and susceptible clones. The resistance phenotype is due to induction of increased periderm cell layers and suberization of the tuber periderm preventing infection. The somaclones provide a valuable resource for further examination of suberization responses and its genetic control.
\end{abstract} parent were examined histologically following challenge with the pathogen and its purified toxin. Relative expression of genes associated with tuber

Potato is the world's third largest staple crop for human consumption after wheat and rice, with global production exceeding 365 million tons per year (FAOSTAT 2015). Potato tubers are covered by specialized skin tissues (periderm), with the outermost corky tissues (phellem) comprising several layers of highly organized, rectangular-shaped suberized cells that provide the primary barrier against desiccation, physical injury, and insect and pathogen attack (Vaughn and Lulai 1991). The efficacy of protection is linked to the rate and extent of phellem and suberin production. For example, thin, smooth-skinned varieties are more susceptible to cosmetic physical damage than many of the russeted varieties that have a greater protective periderm barrier (Lulai 2007). Suberin is a complex biopolyester composed of linked polyaliphatic and polyphenolic domains that are synthesized by phenylalanine ammonia-lyase, anionic peroxidase, and a range of other enzymes (Bernards 2002; Kolattukudy 1981). Due to the large amounts of suberin produced by potato tubers, they have been used as a model system for studying the biosynthesis of aliphatic and phenolic components of suberin (Lulai 2007).

Common scab occurs frequently in most potato-cropping regions of the world. The disease seldom affects yield but production of unsightly and often deep-pitted corky lesions on tubers results in substantial economic losses through reduction in the value of fresh produce, rejection of seed lots that fail to meet certification standards, and losses during processing, where normal steam-peeling processes do not remove all diseased material from deep-pitted lesions, necessitating additional processing steps (Wilson et al. 1999).

Corresponding author: C. R. Wilson; E-mail address: Calum.Wilson@utas.edu.au

*The $\boldsymbol{e}$-Xtra logo stands for "electronic extra" and indicates that two supplementary figures are published online.

http://dx.doi.org/10.1094/PHYTO-08-15-0191-R

(C) 2016 The American Phytopathological Society
Additional keywords: Streptomyces scabies, thaxtomin A.
Streptomyces scabies is the predominant pathogen associated with this disease; however, several additional Streptomyces spp. have been implicated (Dees and Wanner 2012). Pathogenic strains and species produce thaxtomin A, a cyclic nitrated dipeptide phytotoxin, whereas nonpathogenic strains do not (King et al. 1989, 1992). The essential role of thaxtomin A in disease induction has been implicitly demonstrated (Goyer et al. 1998; Kers et al. 2005). Thaxtomin production by pathogenic strains of Streptomyces is stimulated during the pathogen-host interaction by the presence of plant cell wall components and suberin (King and Calhoun 2009). Thaxtomin A inhibits cellulose biosynthesis in expanding plant tissues, induces cell hypertrophy, causes alterations in $\mathrm{H}^{+}$and $\mathrm{Ca}^{2+}$ ion fluxes, causes programmed cell death (Duval et al. 2005; Loria et al. 2003; Tegg et al. 2005), and has been linked with auxin polar transport processes within the cell (Tegg et al. 2013a). There is no single effective management option for this disease; rather, an integrated approach is generally attempted incorporating, where appropriate, cultivar resistance, use of certified seed potato, seed and soil pesticide treatments, strategic use of irrigation, alteration of planting dates, and soil pH manipulation (Dees and Wanner 2012; Lacey and Wilson 2001; Lapwood et al. 1970; Waterer 2002; Wilson et al. 1999).

S. scabies infects tubers through nonsuberized lenticels or by direct penetration through immature tuber periderm tissues (Loria et al. 2003). Disease symptoms reflect induced structural defense responses following infection. Interaction of developing tubers with the pathogen (or with purified thaxtomin A) stimulates periderm cell division and production of a highly suberized corky barrier layer beneath the infection front, which eventually restricts further invasion of tuber tissues (Jones 1931). The depth of a common scab lesion depends upon the virulence of the pathogen and capacity to penetrate the defense layer, inducing a further layer of suberized tissues.

Within the potato-processing sector, cultivar choice is restricted by strict quality parameters of the tuber. These quality demands 
have limited the capacity of potato breeding programs to produce highly resistant cultivars while maintaining other essential agronomic and quality features. 'Russet Burbank' is ideally suited for French fry processing and, although its original selection was over 130 years ago, it remains the most commonly cropped potato cultivar in the world. Russet Burbank is regarded as moderately resistant to common scab; however, substantial epidemics, including occurrence of deep-pitted lesions and associated losses, often occur in this cultivar, especially where disease pressure is high (Wilson et al. 1999). To address this problem, cell selection techniques using thaxtomin $\mathrm{A}$ as a positive selection tool were used to obtain somaclonal variants of Russet Burbank with substantially enhanced resistance to common scab while retaining all the essential agronomic and processing characteristics of this cultivar (Wilson et al. 2010). Unexpectedly, many of these disease-resistant variants did not show enhanced tolerance to thaxtomin $\mathrm{A}$, and the mechanism of enhanced resistance was unknown. Furthermore, most of these variants also showed increased resistance to a variety of tuber-invading diseases, including powdery scab (Tegg et al. 2013b) black scurf, and tuber soft rot (Thangavel et al. 2014) caused by infections with diverse pathogen types.

Given the importance of induced structural defense responses to common scab symptomology and disease development and the fact that thaxtomin A, used for the selection of resistant variants, is known to induce these responses, we tested the hypothesis that the common scab-resistant variants have enhanced induced structural defense responses when compared with the unselected parent, and that the resistant variants can prevent infection through increasing tuber periderm thickness and suberization of the periderm tissues. We used histological approaches to follow pathogen-induced changes in the periderm and measured relative expression of genes associated with suberin biosynthesis over time following exposure to the pathogen. The use of somaclonal variants with altered resistance phenotypes to compare responses provided a unique and important tool, enabling comparisons without confounding effects of cultivar differences.

\section{MATERIALS AND METHODS}

Plant materials. In a prior study, somaclonal variants of Russet Burbank potato were generated using cell selection techniques, with thaxtomin A as a positive selection agent (Wilson et al. 2010). Four somaclonal variants with enhanced resistance to common scab (A168a, A380, TC10-C1, and TC-RB8), one variant with no improved disease resistance (TC9-G1), and the parent Russet Burbank as a control and comparator were evaluated in a series of three pot trials and a field trial for pathogen-induced structural defense responses.

Pot trials. Inoculum was prepared by harvesting spores of pathogenic S. scabies (isolate G32) from a 2-week-old culture grown on ISP2 medium (Shirling and Gottlieb 1966) into $10 \mathrm{ml}$ of sterile water; adding the spores in water to a sterilized mixture of $100 \mathrm{~g}$ of vermiculite and $500 \mathrm{ml}$ of a solution of sucrose at $20 \mathrm{~g} / \mathrm{liter}$, $L$-asparagine at $1.2 \mathrm{~g} / \mathrm{liter}, \mathrm{K}_{2} \mathrm{HPO}_{4}$ at $0.6 \mathrm{~g} / \mathrm{liter}$, and yeast extract at $10 \mathrm{~g} /$ liter ( $\mathrm{pH} 7.2$ ); and incubating the result for 14 days at $24^{\circ} \mathrm{C}$.

Three pot trials were established using a stratified pot technique which enables periodic examination of developing tubers without disturbing plant roots (Khatri et al. 2010). Plastic pots $(20 \mathrm{~cm}$ in diameter, $20 \mathrm{~cm}$ in height, and 4.7 liters in capacity) were filled to $40 \%$ capacity with potting mix containing sand, peat, and composted pine bark (10:10:80; pH 6.0) premixed with Osmocote 16-3.5-10 NPK resin-coated fertilizer (Scotts Australia Pty. Ltd., Baulkham Hills, Australia) at the rate of $6 \mathrm{~kg} / \mathrm{m}^{3}$, over which a fiberglass mesh $(1 \mathrm{~mm})$ was laid. On top of this, a layer of inoculum and potting mix (1:1) or potting mix alone was added, filling the bags to $80 \%$ capacity. Two-week-old tissue-cultured plantlets of the variants and parent control were transplanted into individual pots, carefully placing the roots on the mesh in the upper zone of the pot. In pot trial 1 (PT1), five variants and the parent cultivar were evaluated. PT2 and PT3 compared the variant A380 and the parent control only.

Plants were grown under standard glasshouse conditions (18 to $24^{\circ} \mathrm{C}$ ). At approximately 6 weeks after planting, stolons within the top layer of the pot were gently uncovered (Khatri et al. 2010). Onset of tuber initiation was determined as the date when stolon tips had swollen to twice their diameter (Khatri et al. 2011). Initiating tubers were tagged and dated for subsequent harvest. PT1 had a single harvest 6 weeks after tuber initiation (ati). PT2 and PT3 had five harvests $2,4,6,8$, and 10 weeks ati. For each harvest, three tubers from each treatment were collected for assessment. Tubers were washed and assessed visually for disease severity. Two tissue samples from the second internode on the tuber were taken, avoiding any lesions present. The first was immediately frozen in liquid nitrogen and stored at $-80^{\circ} \mathrm{C}$ until processing for gene expression analysis. The second was stored in $10 \%$ formaldehyde, $5 \%$ acetic acid, and 50\% ethanol (vol/vol) (FAA) at $4{ }^{\circ} \mathrm{C}$ and used for histological examination.

Field trial. A field trial (FT1) was established in November 2011 on a commercial farm in northwest Tasmania on a soil typical of this major potato production region (Lacey and Wilson 2001). Prior to planting, a 1-kg soil sample comprising a composite of 10 100 -g subsamples taken from across the trial site was analyzed for the presence and quantity of DNA of common potato pathogens, including S. scabies (Ophel-Keller et al. 2008). Variants A380 and TC-RB8 and the parent cultivar were planted in a randomized block design, with each clone replicated in three plots of 15 plants. Planting material was disease-free mini-tubers (25 to $30 \mathrm{~g}$ ) produced by glasshouse culture of tissue-cultured plantlets. No pesticide treatments were applied to seed tubers or soil. Fertilizer, foliar fungicide application (for late and early blight control), and irrigation scheduling followed standard commercial practice. Plants emerged approximately 30 days after planting and tuber initiation was 15 days later. At three harvest periods ( 4 and 8 weeks ati and at plant senescence), a random sample of three tubers from two plants was collected from each plot. Tubers were washed and assessed for disease. Tissue samples were taken for gene expression analysis and histological examination. In addition, at plant senescence, all remaining tubers were harvested and assessed for disease, and 50-g pooled peel samples from a random sample of 25 tubers per plot were analyzed for pathogen DNA content by quantitative polymerase chain reaction (qPCR) (Tegg et al. 2014).

Thaxtomin D tuber treatment. Plants of A380 and its parent clone were grown from tissue-cultured plantlets using the stratified pot technique, as described. Synthetically produced thaxtomin $\mathrm{D}$ with the same biological activity of thaxtomin A (Molesworth 2010) was diluted to $3.5 \mu \mathrm{M}$ in distilled water and applied to tubers, attached to plants, at 6 weeks ati in PT4 and PT5 or at 10 weeks ati in PT6 using a misting spray. In PT6, $1 \mathrm{ml}$ of $0.2 \%$ agarose $\left(25^{\circ} \mathrm{C}\right)$ was then applied to the treated tubers to slow evaporation of the thaxtomin-D-containing solution. A distilled-water spray was used as a control. Treated tubers were gently harvested from the plant after $0,1,6,24$, and $48 \mathrm{~h}$ of thaxtomin D treatment in PT4 and PT5; PT6 included three additional harvests at 3, 18, and $72 \mathrm{~h}$ after treatment. Tissue samples were taken for gene expression analysis. PT4, -5, and -6 had two, two, and three replicates per treatment harvest, respectively.

Common scab disease severity assessment. Tubers were assessed for disease severity, measured as the tuber surface area coverage with lesions and scored using a 0 -to- 6 scale, where $0=$ no disease and $0.5=0$ to $1,1=1$ to $5,2=5$ to $10,3=10$ to $30,4=30$ to $50,5=50$ to 70 , and $6=70$ to $100 \%$ disease (Wilson et al. 2009).

Histological examination of the tuber periderm. Tissue blocks ( $50 \mathrm{~mm}$ long and 1 to $2 \mathrm{~mm}$ in thickness) were stored in FAA and hand sectioned using a razor blade. Sections were stained with toludine blue and examined at $\times 100$ magnification (Leica DMLB; Leica Microsystems, Bensheim, Germany), with images captured digitally and cell sizes calculated using the IM1000 image analysis 
software (Leica Microsystems, Heerbrugg, Switzerland). To determine accumulation of the suberin polyphenolic (SPP) domain on the phellem cell walls, the same tissue sections were stained for $60 \mathrm{~min}$ in aqueous $0.1 \%(\mathrm{wt} / \mathrm{vol})$ berberine-hemisulfate, followed by $15 \mathrm{~min}$ in aqueous $0.5 \%(\mathrm{wt} / \mathrm{vol})$ aniline blue and $5 \mathrm{~min}$ in $0.1 \%$ (wt/vol) $\mathrm{FeCl}_{3}$ in $50 \%$ (vol/vol) aqueous glycerol, with samples rinsed in water between staining treatments (Khatri et al. 2011). Sections were viewed at $\times 100$ magnification under UV light to detect SPP autofluorescence (Khatri et al. 2011; Lulai and Corsini 1998). The DMLB microscope was configured for epifluorescent illumination using an HBO103W/2 mercury lamp, excitation filter BP 340 to 380, chromatic beam-splitter FT 400, and barrier filter LP 425. The degree of SPP accumulation on the phellem cell walls in the tuber periderm was scored using a modification of a published rating scale (Lulai and Corsini 1998) (Supplementary Fig. S1).

Gene expression studies. Tuber skin samples $\left(1 \mathrm{~cm}^{2}\right.$ of $0.5 \mathrm{~mm}$ in thickness) were excised from tubers with a scalpel, minimizing any parenchyma tissues, and immediately frozen in liquid nitrogen. Total RNA was then extracted from approximately $50 \mathrm{mg}$ of the tuber skin samples using the PowerPlant pro RNA isolation kit with DNAse (MO BIO Laboratories, Carlsbad, CA), following the manufacturer's protocols. Genomic DNA was eliminated by DNAse treatment during extraction. RNA quantity was determined by fluorescent spectroscopy (Qubit 2.0 fluorimeter; Invitrogen Co., Carlsbad CA) and cDNA was synthesized from RNA at $10 \mathrm{ng} / \mathrm{ml}$ from each sample using the IScript reverse-transcription kit with random hexamer primers (Bio-Rad Laboratories, Inc. Hercules, CA). Suberin biosynthesis-associated genes CYP86A33, StKCS6, and POP_A; jasmonic acid (JA) pathway genes Pin2 and LoxA; ethylene (ET) pathway genes $P R 1 b$ and Osmotin-like; salicylic acid (SA) pathway genes GluA and $P R-1 a$; and two housekeeping genes, previously identified as the most stable in potato for gene expression normalization ( $18 s$ and $\alpha f 1$ ) (Nicot et al. 2005), were selected from published work (Table 1). qPCR was then performed on $1.5 \mu \mathrm{l}$ of 10 -fold-diluted cDNA with a total volume reaction of $10 \mu \mathrm{l}$ using iTaq universal SYBR green supermix (Bio-Rad Laboratories, Inc.). Amplification conditions were $1 \mathrm{~min}$ at $95^{\circ} \mathrm{C}$ followed by 45 cycles of $15 \mathrm{~s}$ at $95^{\circ} \mathrm{C}$ and $30 \mathrm{~s}$ at $60^{\circ} \mathrm{C}$, and melt curve analysis was conducted for $5 \mathrm{~min}$ at $90^{\circ} \mathrm{C}$. Selected amplicons were sequenced to confirm their identity. RNA samples without reversetranscription treatment and nontemplate controls were included in each run to check for genomic contamination.
Data analysis. Mean disease data for all tubers per replicate in each trial were evaluated by analysis of variance (ANOVA) using GENSTAT 14 software (VSN International Ltd., Hemel Hempstead, UK) after ensuring an approximate normal distribution for each variable. The relative fold changes in gene expression were determined using the normalization $2^{-\Delta \Delta C T}$ method (Livak and Schmittgen 2001), with data normalized against the average cycle threshold (CT) of both housekeeping genes. The significance of relative fold changes was determined by ANOVA.

\section{RESULTS}

Common scab assessment. Disease assessments significantly differed between the disease-resistant variants and the susceptible variant and the parent clone in all PT. In PT1, A380, A168a, and TC10-C1 had significantly less disease than the parent and the disease-susceptible clone TC9-G1, which was not different from the parent (Fig. 1). A380 had less disease than TC10-C1. In PT2 and PT3, A380 again had significantly less disease than the parent (Fig. 1). In FT1, the preplant soil test indicated very low inoculum levels, with $S$. scabies DNA detected at only $12 \mathrm{pg} / \mathrm{g}$ of soil. No common scab symptoms were observed on harvested tubers. The average contents of $S$. scabies DNA on the tuber samples were $382 \mathrm{pg} / \mathrm{g}$ of tuber tissue for A380, 3,866 pg/g for TC-RB8, and $416 \mathrm{pg} / \mathrm{g}$ for the parent.

Assessment of accumulation of SPP on phellem cell walls and the number of phellem cell layers. There were significant differences in the number of phellem cell layers and the SPP score between clones in all trials $(P<0.001$ for PT1 to PT3 and FT1). In each PT, addition of the pathogen to the growing medium stimulated an increase in both phellem layers and SPP score $(P<0.001)$, with a significant interaction found between clone and pathogen treatment for phellem cell layer for PT1, PT2, and FT1 $(P=0.006, P<0.001$, and $P<0.001$, respectively) but not PT3 $(P=0.416)$; and for SPP scores for PT1, PT2, and FT1 $(P=0.009, P<0.001$, and $P<0.001$, respectively) but not PT3 $(P=0.058)$. In PT2, PT3, and FT1, the harvest date also significantly affected both the number of phellem cell layers and SPP scores $(P<0.001)$. There were also significant interactions between clone and harvest date $(P=0.05, P<0.001$, and $P<0.001$ for PT2, $\mathrm{PT} 3$, and FT1, respectively); pathogen treatment and harvest date $(P<0.001$ for PT2 and PT3); and clone, pathogen treatment, and harvest date $(P<0.001$ for PT2 and PT3).

TABLE 1. List of primers used in this study

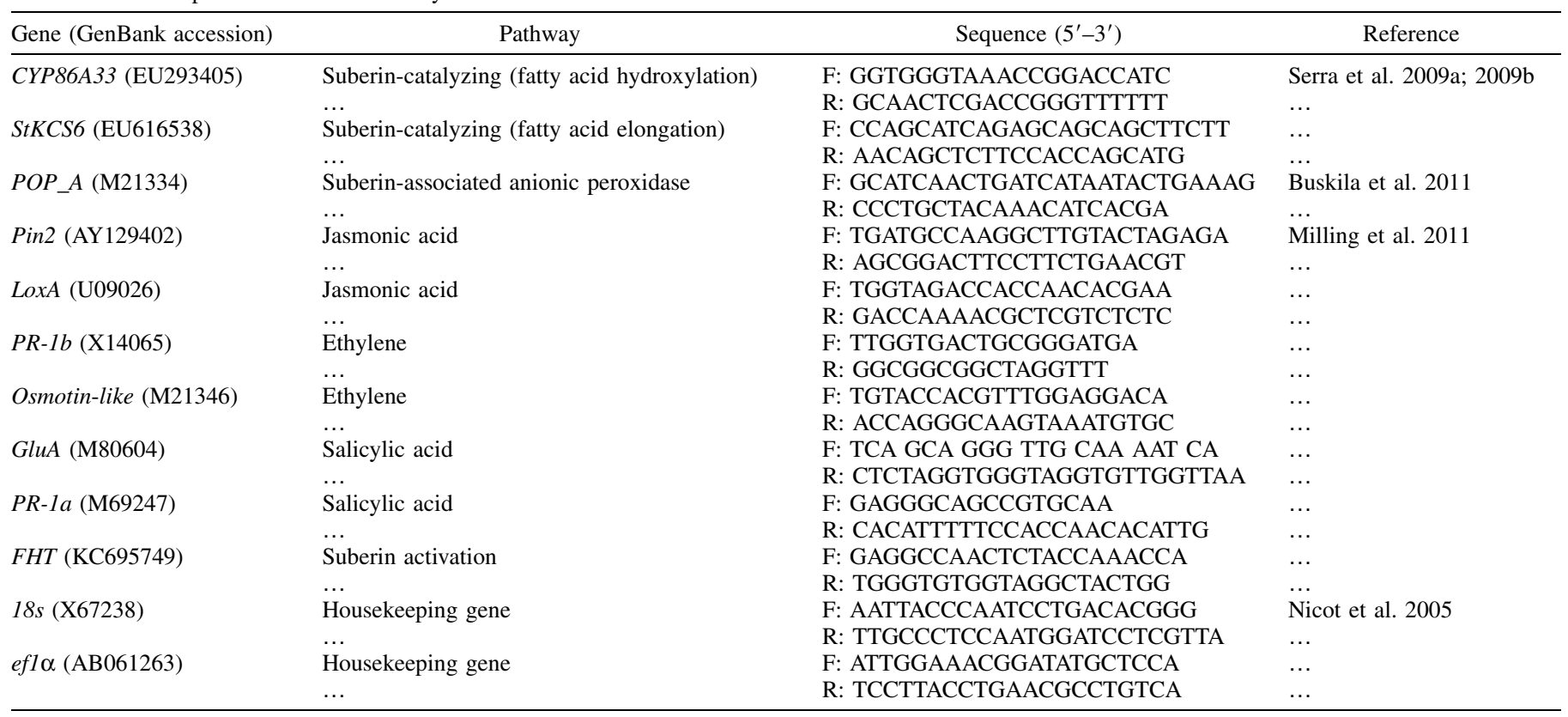


In PT1 in the absence of the pathogen, A380, A168a, and TC10-C1 all had a significantly greater mean number of phellem cell layers than the parent and TC9-G1, with A380 and A168a having more layers than TC10-C1 (Fig. 2). In the presence of the pathogen, A380,
A168a, and TC10-C1 again had greater numbers of cell layers than the parent and TC9-G1 although, this time, A380 had significantly more layers than A168a, which was not different from TC10-C1

(Fig. 2). Similar results were seen for SPP accumulation, with A380

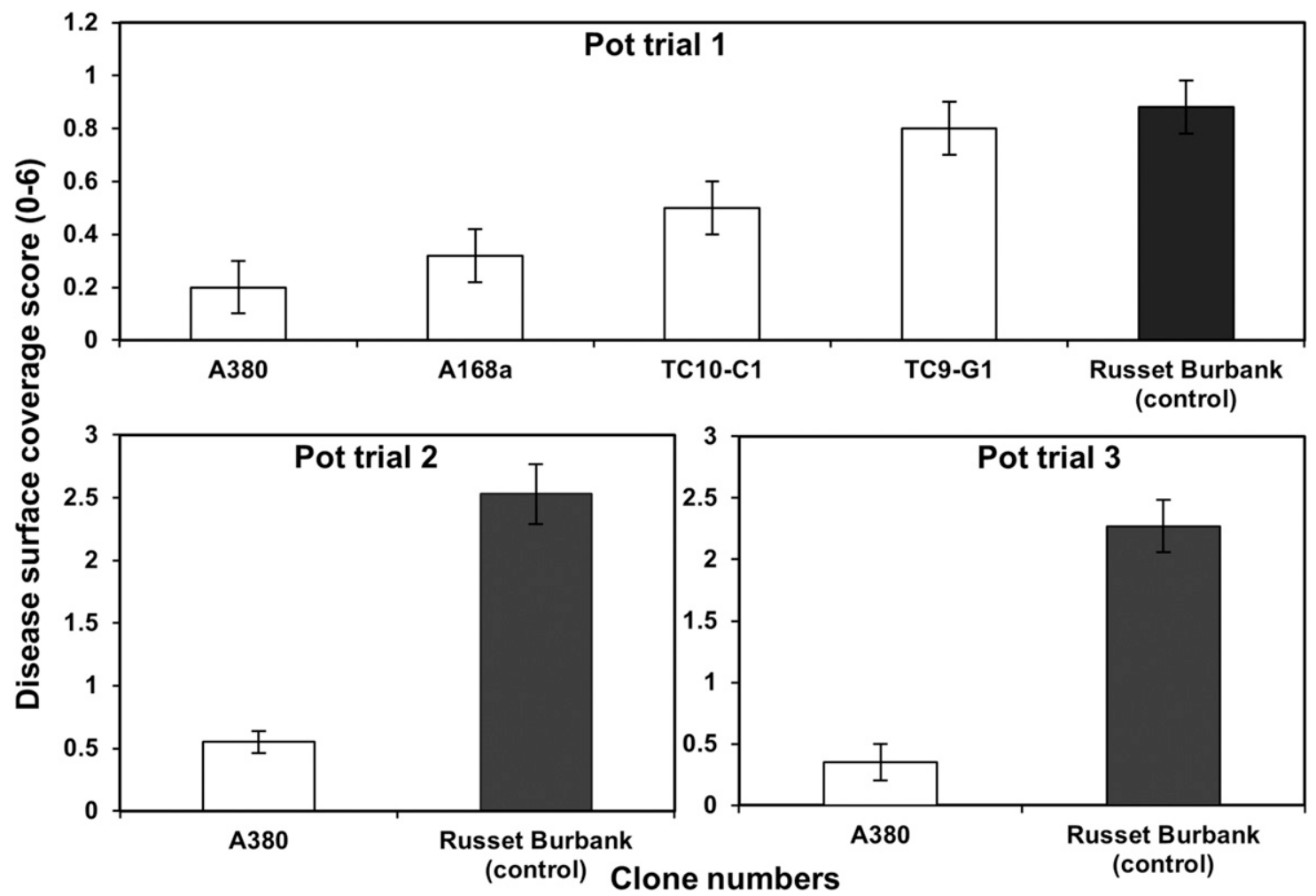

Fig. 1. Comparison of common scab disease severity (surface coverage score of 0 to 6 ) expressed in disease-resistant somaclonal variants and the parent cultivar (Russet Burbank) in pot trials (PT1 to PT3). Error bars are the standard variance, with $n=25, n=30$, and $n=30$ for PT1, PT2, and PT3, respectively.
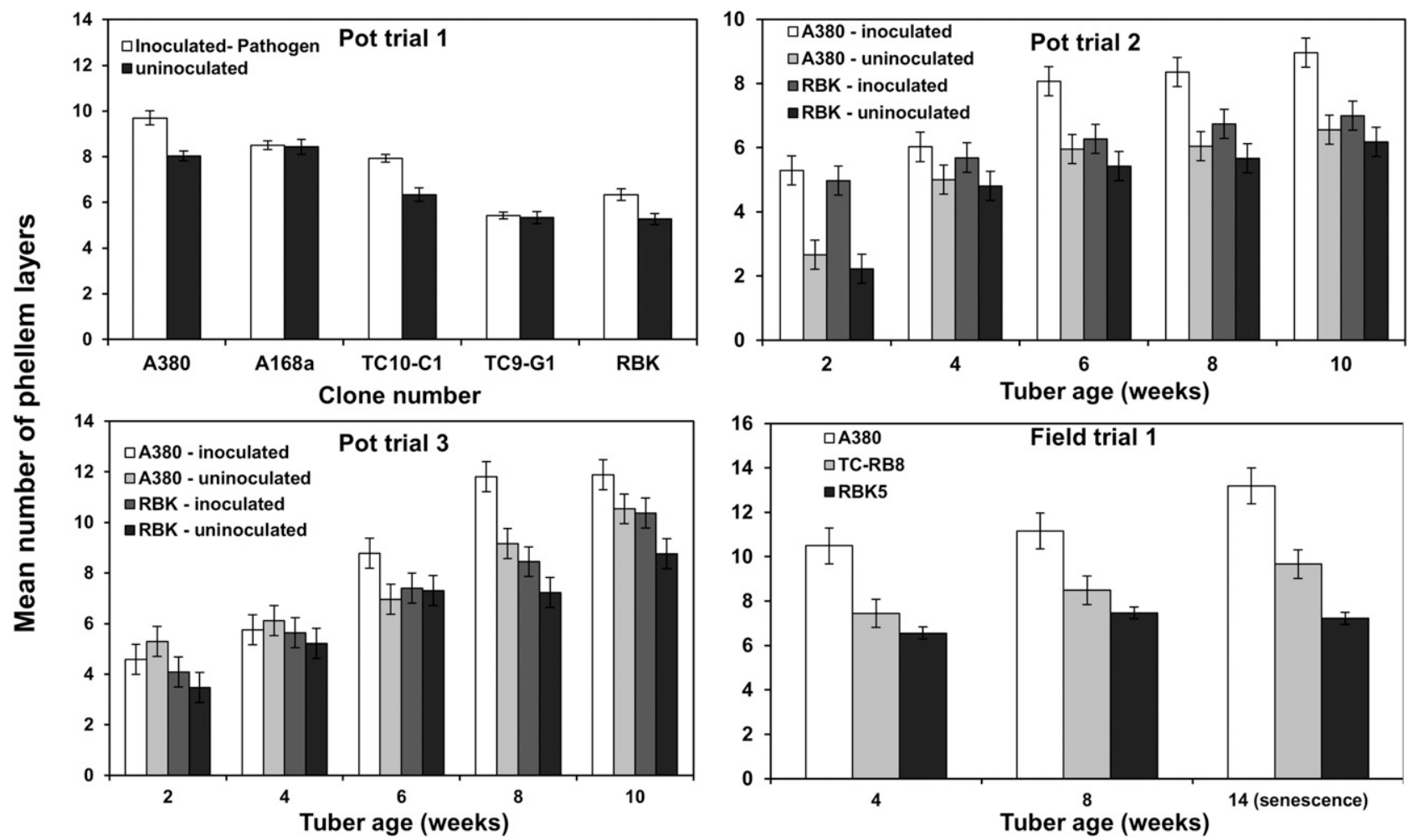

Fig. 2. Variation in tuber phellem cell layers in somaclonal variants and the parent (Russet Burbank [RBK]) induced by exposure to Streptomyces scabies in pot (PT) and field (FT) trials. Error bars are the standard variance, with $n=30, n=45, n=45$, and $n=15$ for PT1, PT2, PT3, and FT1, respectively. 
and A168a having a greater SPP score than TC10-C1, TC9-G1, and the parent in the absence of the pathogen, with the latter three not differing from each other (Fig. 3). In the presence of S. scabies, A380 and A168a had significantly greater SPP scores than TC10-C1, which had a score greater than the parent and TC9-G1 (Fig. 3).

In PT2 and PT3, the number of cell layers and the SPP score increased with harvest date in both varieties. In PT2, in the absence of the pathogen, there was a nonsignificant trend for an increase in cell layer at each harvest (Fig. 2) but a highly significant increase in SPP score (Fig. 3) in A380 compared with the parent. When the pathogen was present, the number of phellem cell layers was increased in A380 relative to the parent control at 6, 8, and 10 weeks ati, and SPP score increased at all harvests (Figs. 2 and 3). In PT3, A380 had a greater number of cell layers at 2, 8, and 10 weeks (Fig. 2) and a greater SPP score at 4, 6, and 10 weeks (Fig. 3) than the parent in the absence of inoculation. When S. scabies was present, A380 had more cell layers and a greater SPP score than both TC-RB 8 and the parent from week 6 onward. In FT1, A380 had a greater number of phellem layers and SPP score than the parent at all harvest dates (Figs. 2 and 3).

Expression of suberin biosynthesis-associated genes. Significant differences were found in the relative expression of $C Y P 86 A 33$, StKCS6, and POP_A genes in the tuber skin tissues of A380 and the parent control in four PT (PT2 to PT6) and FT1 in response to challenge with $S$. scabies and thaxtomin D treatment.

In PT2 and PT3, expression data were compared with levels produced by the noninoculated parent control harvested at 2 weeks ati (Fig. 4). Expression of the three genes was significantly higher in pots treated with $S$. scabies than in noninoculated pots $(P=0.02)$.

In PT2, A380 showed a consistent trend for greater expression of all three genes than the parent. With $C Y P 86 A 33$, these differences were significant at 10 weeks ati; for StKCS6, significant differences showed at 2, 6, and 10 weeks ati; and, for $P O P \_A$, all five harvests showed significant differences (Fig. 4). PT3 showed similar results, with significantly greater gene expression in A380 compared with the parent of CYP86A33 at 8 and 10 weeks ati, StKCS6 at 2 to
10 weeks ati, and $P O P_{\_} A$ at all harvests expect week 4 (Fig. 4). There were no significant interactions $(P>0.05)$ between clone and tuber age for any of the three genes in either PT2 or PT3.

In FT1, expression data were compared with levels produced by 4-week-old tubers of the parent control. There was significantly greater expression of CYP86A33, StKCS6, and POP_A in A380 than in TC-RB8 which, in turn, had greater expression than the parent control at both initial and senescence assessments; however, no significant effect was found at the 8-week harvest except for StKCS6, where A380 again showed enhanced expression. Tubers assessed at haulm senescence had significantly higher expression of all three genes than those sampled at the earlier assessments $(P=0.02)$.

In PT4 and PT5, following thaxtomin D application to 6-week-old tubers, and PT6, where thaxtomin D treatment was applied to 10-week-old tubers, A380 showed significantly higher expression of $C Y P 86 A 33$ than the parent $(P<0.001,0.025$, and 0.001 , respectively) (Fig. 5). Enhanced stimulation of gene expression was not observed until $6 \mathrm{~h}$ (PT5) or $24 \mathrm{~h}$ (PT4 and PT6) after the treatment. Similarly, StKCS6 gene expression was significantly higher in A380 than the parent line in all three trials following thaxtomin D treatment $(P=0.001,0.009$, and 0.01 , respectively). In PT4, StKCS6 has significantly greater expression in A380 from $1 \mathrm{~h}$ after the thaxtomin treatment whereas, in PT5 and PT6, significant differences were seen at 6 and $18 \mathrm{~h}$ respectively. A380 again showed greater $P O P \_A$ expression than the parent in all three trials $(P<0.001,0.001$, and 0.01, respectively) (Fig. 5). Commencement of significant greater expression occurred at $6 \mathrm{~h}$ (PT5 and PT6) or $24 \mathrm{~h}$ (PT4).

Thaxtomin D-induced expression of innate defense genes. Stimulation of the various genes associated with the innate defense pathways (JA, SA, and ET) occurred following thaxtomin D treatment commencing at times from 1 to $24 \mathrm{~h}$ (Fig. 6). However, with the exception of Pin $2(P=0.006)$, there were no significant differences found between A380 and the parent clone. Examination of individual assessment times again suggested no differences
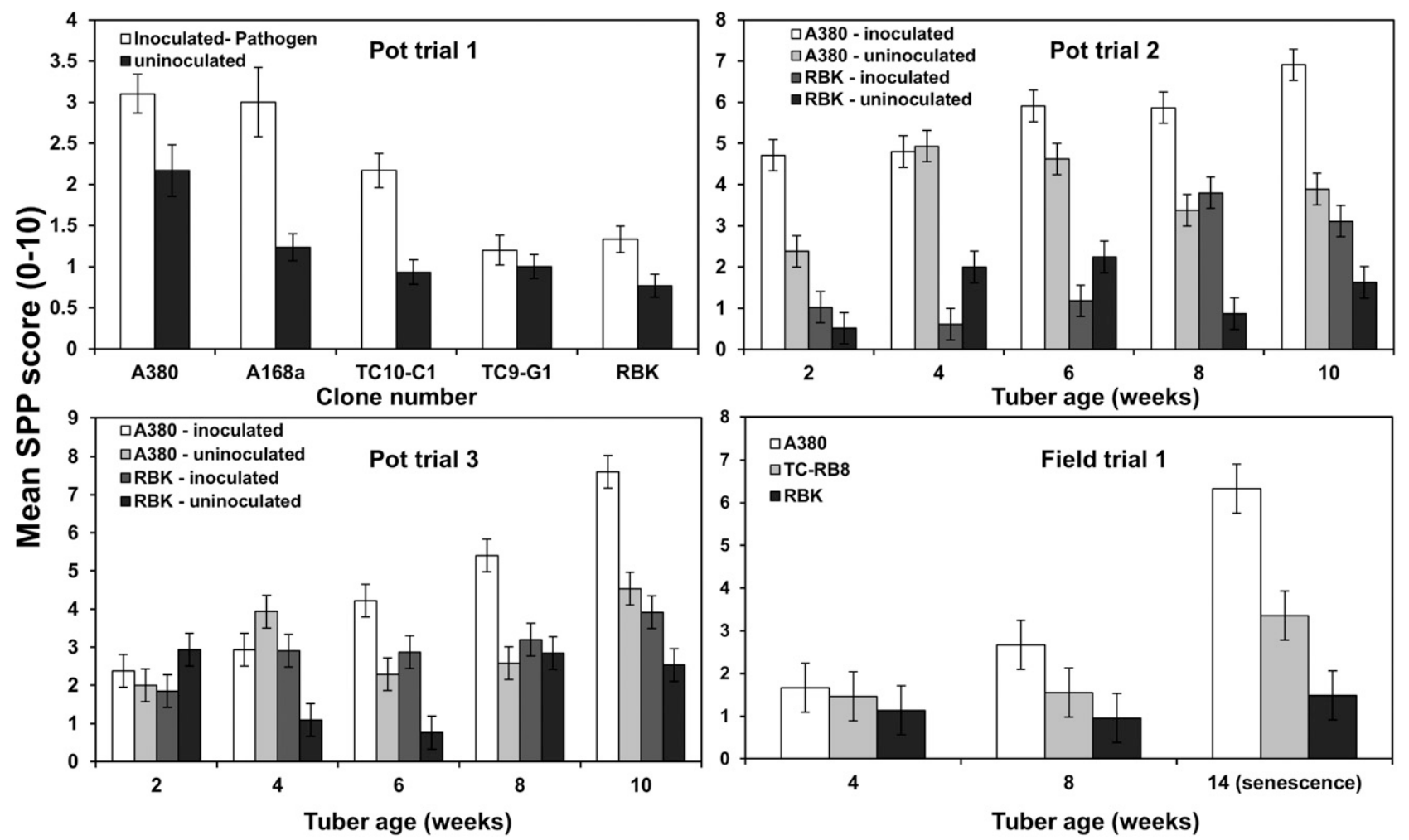

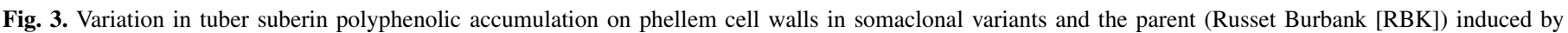

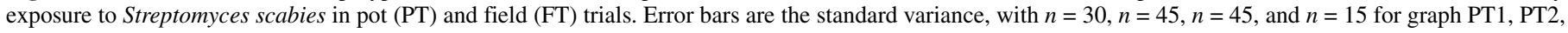
PT3, and FT1, respectively. 
between A380 and the parent (except for a possible differential stimulation of LoxA at $24 \mathrm{~h}$ in A380).

\section{DISCUSSION}

Plants have evolved complex defensive mechanisms that include both constitutive and pathogen-induced components (Apel and Hirt 2004; Beisson et al. 2012). In plants, the cell wall and cuticle is the first line of defense against pathogen penetration. The constitutive structural barriers are supported by pathogen-induced defense processes. These include the production of reactive oxygen species with antimicrobial activity followed by a cascade of defense responses, including production of phenolic biopolymers such as SPP within peridermal cells (Bernards et al. 2004; Kolattukudy 1981; Zhao and Dixon 2014). With potato, tubers grown within the soil system have an increased interaction with microbes and potential pathogens compared with the plant's aboveground parts. Lenticels and stomata in tubers provide possible pathways for pathogen entrance (Adams 1975). In tubers, induced production of suberin within the periderm plays a vital role in repairing skin damage, inhibiting fungal and bacterial penetration, and preventing water loss from bruised tubers (Lulai 2007).

Plant cell-wall-associated defense mechanisms are complex processes and only partially understood. However, pathogen-triggered suberization (Beisson et al. 2012; Lulai 2005) is well documented in different plants, including Arabidopsis (Franke et al. 2005), wheat (Southerton and Deverall 1990), strawberry (Amil-Ruiz et al. 2011), tomato (Quiroga et al. 2000), and potato (Kolattukudy 1981; Lulai and Corsini 1998; Serra et al. 2009a,b). During initial pathogen-host interactions, several defense signaling genes may be activated, producing antimicrobial compounds and stimulating the production of structural and chemical barriers to infection. Failure to mount an effective defense response will lead to host infection. Suberin biosynthesis and accumulation is a complex process which is activated independently from the innate host immunity signaling pathways (Bernards et al. 2004; Zhao and Dixon 2014). Recently, genes associated with suberin biosynthesis and deposition have been described and used to monitor dynamics of suberization induction following pathogen attack and wounding (Buskila et al. 2011; Soler et al. 2007) (Supplementary Fig. S2). Elevation of expression of these genes is associated with induced defense mechanisms against pathogen invasion and cell-walldegrading enzymes (Zhao and Dixon 2014). CYP86A33 is a putative $\omega$-hydrolase believed to be responsible for $\omega$-terminal synthesis of very long chain fatty acids (VLCFA) in potato (Höfer et al. 2008; Serra et al. 2009b), StKCS6 is a putative ketoacyl-coA synthase candidate responsible for the elongation of VLCFA (Lee et al. 2009; Serra et al. 2009a), and POP_A is a peroxidase responsible for $\mathrm{H}_{2} \mathrm{O}_{2}$-mediated production of SPP (Bernards et al. 2004; Quiroga et al. 2000; Roberts et al. 1988). Peroxidase genes such as $P O P \_A$ are generally associated with skin injury (Spoel et al. 2007). In potato, RNA interference (RNAi)-mediated silencing of CYP86A33 and StKCS6 resulted in reduced production of suberin in potato (Serra et al. 2009a,b). These three genes are highly expressed following Rhizoctonia solani infection or wounding in potato tubers (Buskila et al. 2011; Lulai and Neubauer 2014).

In prior research, a cell-selection method was used to obtain somaclonal variants of Russet Burbank potato with enhanced
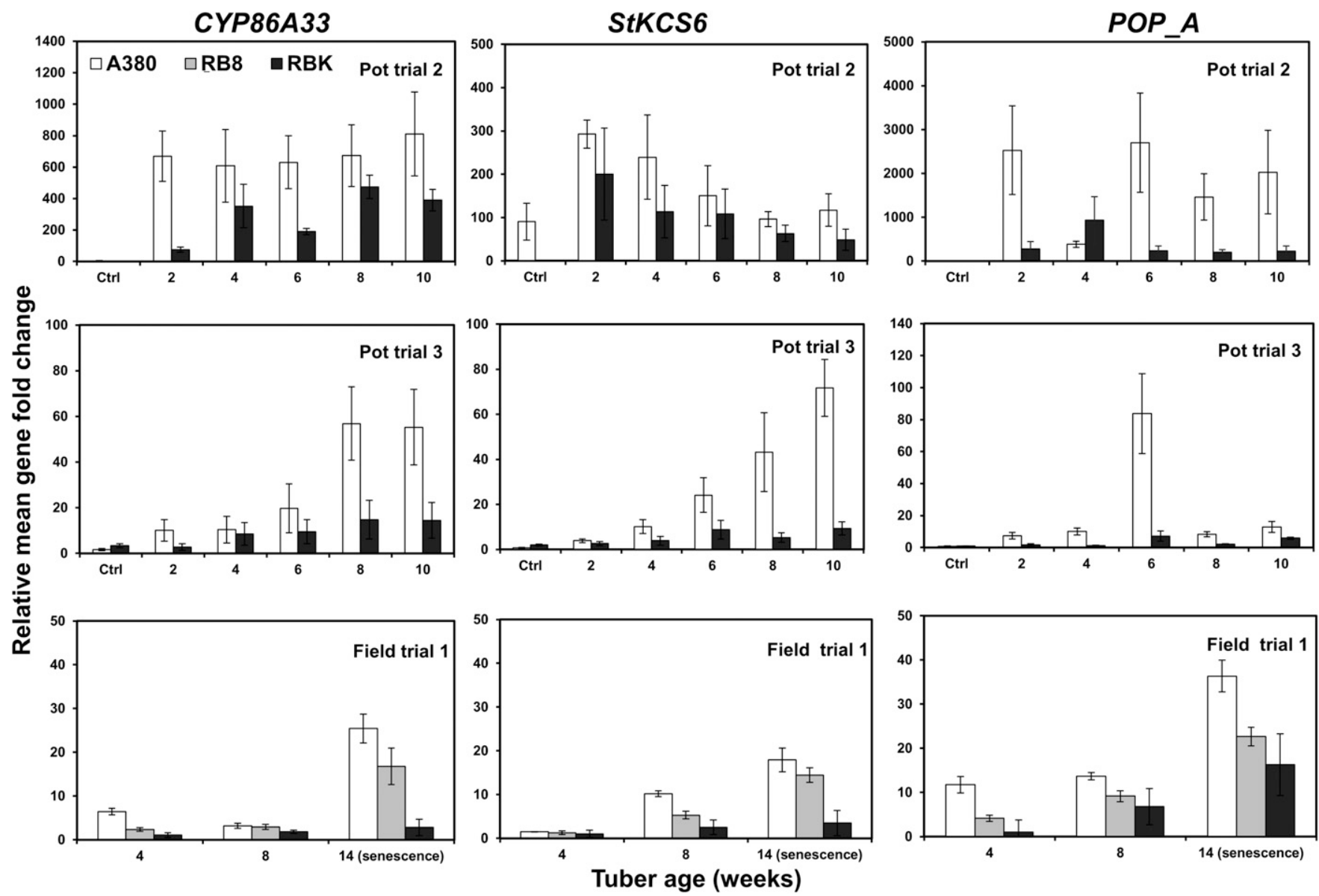

Fig. 4. Effect of Streptomyces scabies exposure on the relative expression of suberin biosynthesis-associated genes CYP86A33, StKCS6, and POP_A within tuber tissues from the second internode of variants A380 and its parent (Russet Burbank [RBK]) measured by quantitative polymerase chain reaction in time-course studies in pot (PT) and field (FT) trials. Treatment differences were compared with gene expression in the noninoculated parent sampled at 2 weeks (PT2 and PT3) or 4 weeks (FT1). Error bars are the standard variance, with $n=6, n=6$, and $n=9$ for PT2, PT3, and FT1, respectively. 
common scab resistance, using thaxtomin A as a positive selection agent (Wilson et al. 2010). These common scab-resistant clone variants were subsequently shown to also have enhanced resistance to other diverse tuber-invading pathogens, including Spongospora subterranea, $R$. solani, Pectobacterium atrosepticum, and P. carotovorum (Tegg et al. 2013b; Thangavel et al. 2014); however, this enhanced resistance to tuber disease was not extended to roots or stolons (Thangavel et al. 2014). For common scab, the pathogen Streptomyces scabies enters through nonsuberized lenticels or directly through the immature tuber periderm in young, rapidly developing tubers. Most successful infections with this pathogen occur within 1 to 6 weeks of tuber initiation. Following infection, the plant responds by producing highly suberized cork cells that provide a barrier to further invasion of the tuber and are the basis of the scab symptoms (Jones 1931). Previous studies have shown a strong correlation between the failure of tuber periderm suberization and successful S. scabies proliferation into the tuber periderm (Jones 1931). Direct thaxtomin A treatment of tubers has been shown to induce a similar response to the pathogen (Lawrence et al. 1990). In this study, periderm structure and SPP biosynthesis and deposition were examined within susceptible tuber tissues challenged with $S$. scabies or treated with purified thaxtomin D, using histology and gene expression methods to determine any association between these defense responses and enhanced common scab resistance in the variants of Russet Burbank. We found that significantly greater expression of genes associated with suberin synthesis, increased accumulation of SPP, and an increased number of phellem layers within the tuber periderm occurred in response to $S$. scabies and thaxtomin D treatment in the disease-resistant clones in comparison with the parent cultivar across all trials. We concluded that this could be one of the primary mechanisms for the enhanced common scab resistance phenotype. Increased phellem layers and SPP accumulation were also generally observed in A380 compared with the parent in the absence of the pathogen, suggesting that some constitutive expression in A380 or other tuber stresses triggered this defense response. Increased SPP accumulation supports previous studies that showed that greater production of suberin in response to pathogen infection may inhibit pathogen penetration (Lee et al. 1992). Our findings build upon these and similar prior studies (Fox et al. 1971; Lee et al. 1992; Vaughn and Lulai 1991) by comparing somaclonal variants with near-identical genetic backgrounds that differ only in the disease resistance response. Previously, studies have shown that rapid suberization within $8 \mathrm{~h}$ had a major role in resisting infection of tomato plants by Verticillium albo-atrum (Lee et al. 1992). Similarly, resistant and susceptible potato varieties showed more rapid tuber suberization in response to $V$. dahliae inoculation (Vaughn and Lulai 1991). Absence of suberin in the tuber periderm has also been shown to increase the tuber susceptibility to diseases. Also, application of isopropyl N-(3-chlorophenyl) carbamate to plants, which inhibits the suberin production in the tuber periderm, resulted in greater tuber soft rot when challenged with $P$. carotovorum (Audia et al. 1962).

Suberized cell-wall layers can be classified based on tissue specificity and suberin structure, whether it has predominantly SPP or suberin polyaliphatic (SPA) domains (Bernards 2002; Lulai and Corsini 1998). The contiguous accumulation of SPP on the outer tangential cell walls was found to block bacterial infection of potato
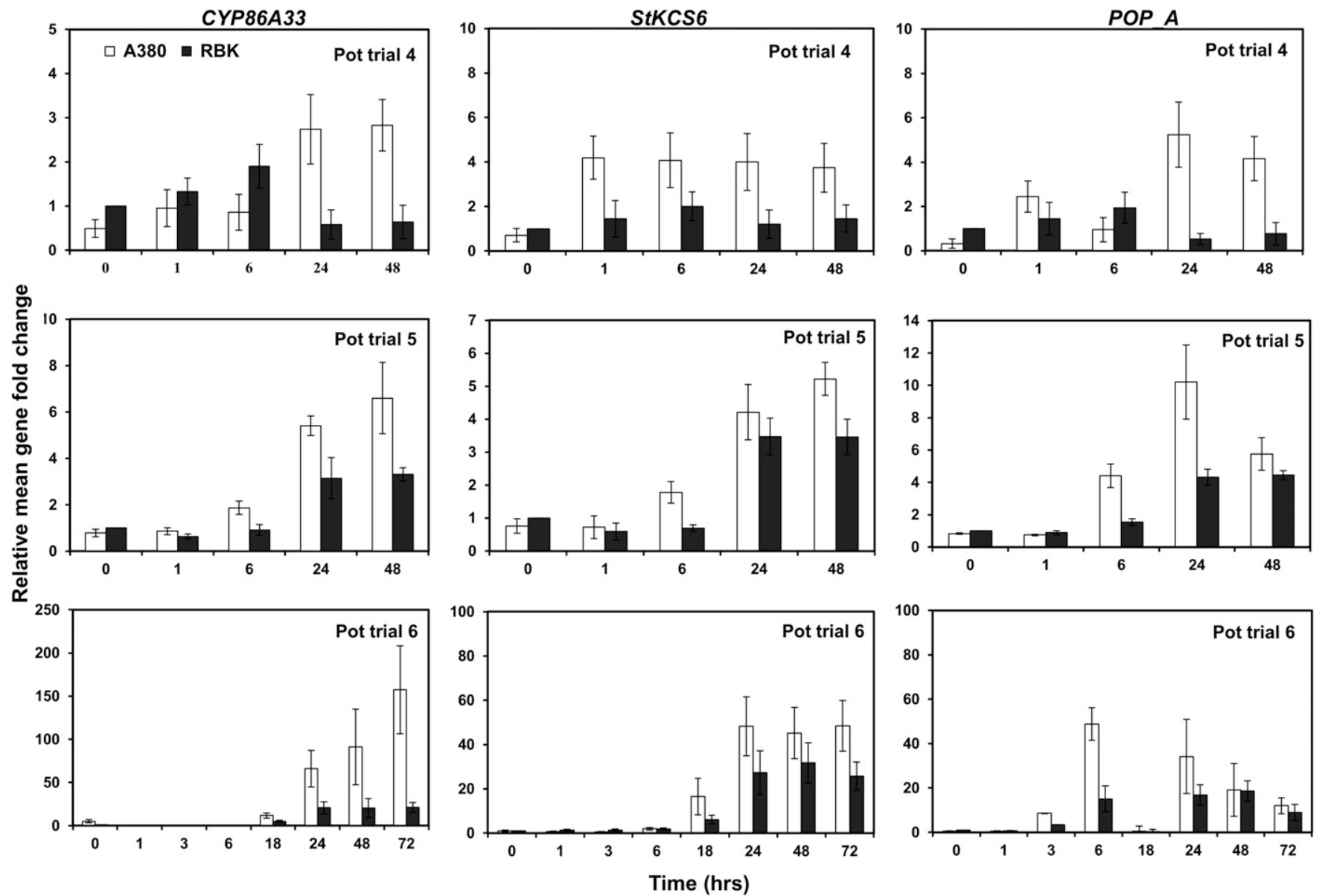

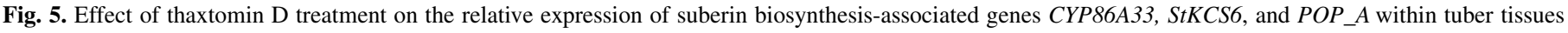

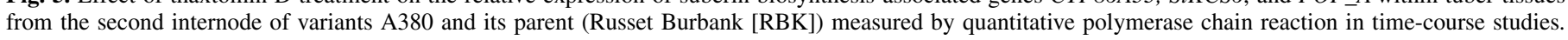

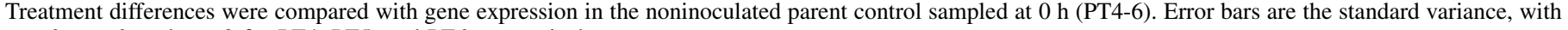
$n=6, n=6$, and $n=9$ for PT4, PT5, and PT6, respectively. 
tubers with $P$. carotovorum but not the fungal pathogen Fusarium sambucinum (Lulai and Corsini 1998). This study indicated that the SPP did not restrict the fungal pathogen; therefore, fungal penetration could occur after the erection of an SPP barrier to bacterial infection but prior to the resistance provided by the SPA barrier. Given the importance of suberin aliphatic domains, several studies have described the role of suberin aliphatic domains, and candidate genes for synthesizing those suberin aliphatic domains have been investigated. Lulai (2007) stated that pathogen factors might be involved in synthesis of SPP and SPA. In the work presented in this article, we did not attempt to examine the differential expression of SPP and SPA.

In this gene-expression study, the disease-resistant somaclonal variants showed greater expression levels of three genes associated with suberin biosynthesis within potato skin tissues in response to S. scabies inoculation and thaxtomin D treatment. This supports the histological data showing enhanced periderm suberization, and previous studies (Lulai 2007; Lulai and Corsini 1998). The time of initial onset of enhanced gene expression following $S$. scabies challenges was somewhat variable. In PT2, significant differences between A380 and control were not expressed until 6 weeks after inoculation whereas, in PT3, these differences were evident from the first assessment at 2 weeks post tuber initiation. FT1 showed significant differences at 4 or 8 weeks, depending upon the gene studied. Thaxtomin D application gave enhanced gene expression at or before $24 \mathrm{~h}$ post treatment. We postulate that, in pathogen pot and field challenges, the time of initial interaction between the pathogen and tuber may vary with inoculum density and environmental conditions. Also, if thaxtomin is required for induction of the suberin response, as we believe, there may be an additional time requirement for the pathogen to initiate thaxtomin synthesis (Bignell et al. 2014).

To confirm the specificity of the induced increase in the number of phellem cell layers and accumulation of autofluorescent SPP as a guideline to suberization, we assessed the effect of thaxtomin $\mathrm{D}$ treatment on gene expression associated with innate defense
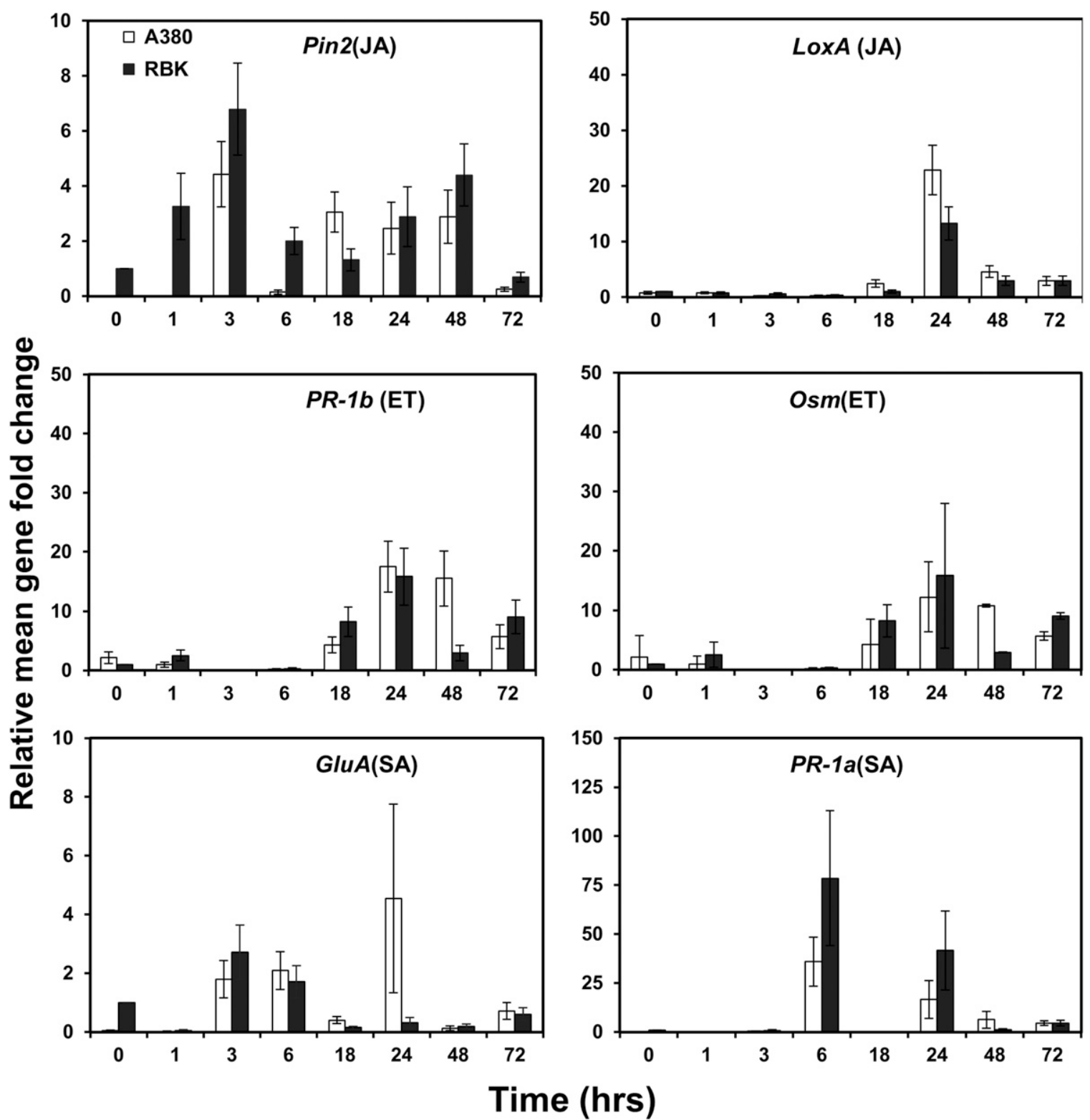

Fig. 6. Effect of thaxtomin D treatment on the relative expression of innate defense pathway genes within the jasmonic acid (JA), ethylene (ET), and salicylic acid (SA) pathways within tuber tissues from the second internode of variants A380 and its parent (Russet Burbank [RBK]) measured by quantitative polymerase chain reaction in a time-course study. Treatment differences were compared with gene expression in the nontreated parent control sampled at $0 \mathrm{~h}$. Error bars are standard variance, with $n=9$. 
responses (SA, JA, and ET pathways). Although treatment generally resulted in upregulation of the defense signaling genes, these were not differentially expressed between variant and parent cultivar. This suggested that these defense pathways are not associated with the enhanced resistance phenotype observed (Bernards 2002; Bernards et al. 2004; Lulai 2007).

In conclusion, the disease-resistant somaclonal variant A380 does have enhanced tuber skin defenses compared with its diseasesusceptible parent. Presence of the common scab pathogen or its toxin results in an induced increase in the number of phellem cell layers in the tuber periderm and greater accumulation of SPP within these tissues. Although not directly measured by the staining techniques used, given demonstrated improved resistance to both fungal and bacterial pathogens (Thangavel et al. 2014), we can be confident that SPA content of the tuber periderm is also enhanced. Absence of differential expression of innate defense pathway activity suggests these enhanced tuber skin defenses are likely the primary factors responsible for the disease resistance phenotype.

\section{ACKNOWLEDGMENTS}

We thank R. Corkrey for assistance with statistical analysis and A. Wilson and A. Gracie for technical support and assistance with histology studies.

\section{LITERATURE CITED}

Adams, M. J. 1975. Potato tuber lenticels: Susceptibility to infection by Erwinia carotovora var. atroseptica and Phytophthora infestans. Ann. Appl. Biol. 79:275-282.

Amil-Ruiz, F., Blanco-Portales, R., Muñoz-Blanco, J., and Caballero, J. L. 2011. The strawberry plant defense mechanism: A molecular review. Plant Cell Physiol. 52:1873-1903.

Apel, K., and Hirt, H. 2004. Reactive oxygen species: Metabolism, oxidative stress, and signal transduction. Annu. Rev. Plant Biol. 55:373-399.

Audia, W. V., Smith, W. L., Jr., and Craft, C. C. 1962. Effects of isopropyl $\mathrm{N}$-(3-chlorophenyl) carbamate on suberin, periderm, and decay development by Katahdin potato slices. Bot. Gaz. 123:255-258.

Beisson, F., Li-Beisson, Y., and Pollard, M. 2012. Solving the puzzles of cutin and suberin polymer biosynthesis. Curr. Opin. Plant Biol. 15:329-337.

Bernards, M. A. 2002. Demystifying suberin. Can. J. Bot. 80:227-240.

Bernards, M. A., Summerhurst, D. K., and Razem, F. A. 2004. Oxidases, peroxidases and hydrogen peroxide: The suberin connection. Phytochem. Rev. 3:113-126.

Bignell, D. R., Francis, I., Fyans, J., and Loria, R. 2014. Thaxtomin A production and virulence are controlled by several bld gene global regulators in Streptomyces scabies. Mol. Plant-Microbe Interact. 27:875-885.

Buskila, Y., Tsror, L., Sharon, M., Teper-Bamnolker, P., Holczer-Erlich, O., Warshavsky, S., Ginzberg, I., Burdman, S., and Eshel, D. 2011. Postharvest dark skin spots in potato tubers are an oversuberization response to Rhizoctonia solani infection. Phytopathology 101:436-444.

Dees, M. W., and Wanner, L. A. 2012. In search of better management of potato common scab. Potato Res. 55:249-268.

Duval, I., Brochu, V., Simard, M., Beaulieu, C., and Beaudoin, N. 2005. Thaxtomin A induces programmed cell death in Arabidopsis thaliana suspension-cultured cells. Planta 222:820-831.

FAOSTAT. 2015. Compare data. Online publication. Food and Agriculture Organization of the United Nations, Statistics Division. http://faostat3.fao. org/compare/E

Fox, R., Manners, J., and Myers, A. 1971. Ultrastructure of entry and spread of Erwinia carotovora var. atroseptica into potato tubers. Potato Res. 14: 61-73.

Franke, R., Briesen, I., Wojciechowski, T., Faust, A., Yephremov, A., Nawrath, C., and Schreiber, L. 2005. Apoplastic polyesters in Arabidopsis surface tissues-A typical suberin and a particular cutin. Phytochemistry 66:2643-2658

Goyer, C., Vachon, J., and Beaulieu, C. 1998. Pathogenicity of Streptomyces scabies mutants altered in thaxtomin A production. Phytopathology 88: 442-445.

Höfer, R., Briesen, I., Beck, M., Pinot, F., Schreiber, L., and Franke, R. 2008. The Arabidopsis cytochrome P450 CYP86A1 encodes a fatty acid $\omega$-hydroxylase involved in suberin monomer biosynthesis. J. Exp. Bot. 59:2347-2360.

Jones, A. P. 1931. The histogeny of potato scab. Ann. Appl. Biol. 18:313-333.

Kers, J. A., Cameron, K. D., Joshi, M. V., Bukhalid, R. A., Morello, J. E., Wach, M. J., Gibson, D. M., and Loria, R. 2005. A large, mobile pathogenicity island confers plant pathogenicity on Streptomyces species. Mol. Microbiol. 55: 1025-1033

Khatri, B. B., Tegg, R. S., Brown, P. H., and Wilson, C. R. 2010. Infection of potato tubers with the common scab pathogen Streptomyces scabiei in a soil less system. J. Phytopathol. 158:453-455.

Khatri, B. B., Tegg, R. S., Brown, P. H., and Wilson, C. R. 2011. Temporal association of potato tuber development with susceptibility to common scab and Streptomyces scabiei induced responses in the potato periderm. Plant Pathol. 60:776-786.

King, R. R., and Calhoun, L. A. 2009. The thaxtomin phytotoxins: Sources, synthesis, biosynthesis, biotransformation and biological activity. Phytochemistry 70:833-841

King, R. R., Lawrence, C. H., and Calhoun, L. A. 1992. Chemistry of phytotoxins associated with Streptomyces scabies the causal organism of potato common scab. J. Agric. Food Chem. 40:834-837.

King, R. R., Lawrence, C. H., Clark, M. C., and Calhoun, L. A. 1989. Isolation and characterization of phytotoxins associated with Streptomyces scabies. J. Chem. Soc. Chem. Commun. 13:849-850.

Kolattukudy, P. E. 1981. Structure, biosynthesis, and biodegradation of cutin and suberin. Annu. Rev. Plant Physiol. 32:539-567.

Lacey, M. J., and Wilson, C. R. 2001. Relationship of common scab incidence of potatoes grown in Tasmanian ferrosol soils with $\mathrm{pH}$, exchangeable cations and other chemical properties of those soils. J. Phytopathol. 149: 679-683.

Lapwood, D., Wellings, L., and Rosser, W. 1970. The control of common scab of potatoes by irrigation. Ann. Appl. Biol. 66:397-405.

Lawrence, C. H., Clark, M. C., and King, R. R. 1990. Induction of common scab symptoms in aseptically cultured potato tubers by the vivotoxin, Thaxtomin. Phytopathology 80:606-608.

Lee, S. B., Jung, S. J., Go, Y. S., Kim, H. U., Kim, J. K., Cho, H. J., Park, O. K., and Suh, M. C. 2009. Two Arabidopsis 3-ketoacyl CoA synthase genes, $K C S 20$ and $K C S 2 / D A I S Y$, are functionally redundant in cuticular wax and root suberin biosynthesis, but differentially controlled by osmotic stress. Plant J. 60:462-475.

Lee, S.-W., Nazar, R. N., Powell, D. A., and Robb, J. 1992. Reduced PAL gene suppression in Verticillium-infected resistant tomatoes. Plant Mol. Biol. 18: $345-352$.

Livak, K. J., and Schmittgen, T. D. 2001. Analysis of relative gene expression data using real-time quantitative PCR and the $2^{-\Delta \Delta C T}$ method. Methods 25 : 402-408

Loria, R., Coombs, J., Yoshida, M., Kers, J., and Bukhalid, R. 2003. A paucity of bacterial root diseases: Streptomyces succeeds where others fail. Physiol. Mol. Plant Pathol. 62:65-72.

Lulai, E. C. 2005. Non-wound induced suberization of tuber parenchyma cells: A physiological response to the wilt disease pathogen Verticillium dahliae. Am. J. Potato Res. 82:433-440.

Lulai, E. C. 2007. Skin-set, wound healing, and related defects. Pages 471-500 in: Potato Biology and Biotechnology: Advances and Perspectives, 1st ed. D. Vreugdenhil, J. Bradshaw, C. Gebhardt, F. Govers, D. K. L. MacKerron, M. A. Taylor, and H. A. Ross, eds. Elsevier, Amsterdam.

Lulai, E. C., and Corsini, D. L. 1998. Differential deposition of suberin phenolic and aliphatic domains and their roles in resistance to infection during potato tuber (Solanum tuberosum L.) wound-healing. Physiol. Mol. Plant Pathol. 53:209-222.

Lulai, E. C., and Neubauer, J. D. 2014. Wound-induced suberization genes are differentially expressed, spatially and temporally, during closing layer and wound periderm formation. Postharvest Biol. Technol. 90:24-33.

Milling, A., Babujee, L., and Allen, C. 2011. Ralstonia solanacearum extracellular polysaccharide is a specific elicitor of defense responses in wiltresistant tomato plants. PLoS One 6:e15853.

Molesworth, P. P. 2010. Studies on the synthesis of biologically active, small molecule natural products. Ph.D. thesis, University of Tasmania Hobart, Tasmania, Australia.

Nicot, N., Hausman, J.-F., Hoffmann, L., and Evers, D. 2005. Housekeeping gene selection for real-time RT-PCR normalization in potato during biotic and abiotic stress. J. Exp. Bot. 56:2907-2914.

Ophel-Keller, K., McKay, A., Hartley, D., and Curran, J. 2008. Development of a routine DNA-based testing service for soilborne diseases in Australia. Australas. Plant Pathol. 37:243-253.

Quiroga, M., Guerrero, C., Botella, M. A., Barceló, A., Amaya, I., Medina, M. I., Alonso, F. J., de Forchetti, S. M., Tigier, H., and Valpuesta, V. 2000. A tomato peroxidase involved in the synthesis of lignin and suberin. Plant Physiol. 122:1119-1128.

Roberts, E., Kutchan, T., and Kolattukudy, P. E. 1988. Cloning and sequencing of cDNA for a highly anionic peroxidase from potato and the induction of its mRNA in suberizing potato tubers and tomato fruits. Plant Mol. Biol. 11: $15-26$.

Serra, O., Soler, M., Hohn, C., Franke, R., Schreiber, L., Prat, S., Molinas, M., and Figueras, M. 2009a. Silencing of StKCS6 in potato periderm leads to 
reduced chain lengths of suberin and wax compounds and increased peridermal transpiration. J. Exp. Bot. 60:697-707.

Serra, O., Soler, M., Hohn, C., Sauveplane, V., Pinot, F., Franke, R., Schreiber, L., Prat, S., Molinas, M., and Figueras, M. 2009b. CYP86A33-targeted gene silencing in potato tuber alters suberin composition, distorts suberin lamellae, and impairs the periderm's water barrier function. Plant Physiol. 149:1050-1060.

Shirling, E. B., and Gottlieb, D. 1966. Methods for characterization of Streptomyces species. Int. J. Syst. Bacteriol. 16:313-340.

Soler, M., Serra, O., Molinas, M., Huguet, G., Fluch, S., and Figueras, M. 2007. A genomic approach to suberin biosynthesis and cork differentiation. Plant Physiol. 144:419-431.

Southerton, S., and Deverall, B. 1990. Histochemical and chemical evidence for lignin accumulation during the expression of resistance to leaf rust fungi in wheat. Physiol. Mol. Plant Pathol. 36:483-494.

Spoel, S. H., Johnson, J. S., and Dong, X. 2007. Regulation of tradeoffs between plant defenses against pathogens with different lifestyles. Proc. Natl. Acad. Sci. USA 104:18842-18847.

Tegg, R. S., Corkrey, R., and Wilson, C. R. 2014. A comparison of potato seed-tuber sampling strategies using visual and DNA analyses to estimate incidence of major seed tuber-borne pathogens. Eur. J. Plant Pathol. 139: 359-367.

Tegg, R. S., Melian, L., Wilson, C. R., and Shabala, S. S. 2005. Plant cell growth and ion flux responses to the streptomycete phytotoxin thaxtomin A: Calcium and hydrogen flux patterns revealed by the non-invasive MIFE technique. Plant Cell Physiol. 46:638-648.

Tegg, R. S., Shabala, S. N., Cuin, T. A., Davies, N. W., and Wilson, C. R. 2013a. Enhanced resistance to the cellulose biosynthetic inhibitors, thaxtomin A and isoxaben in Arabidopsis thaliana mutants, also provides specific co-resistance to the auxin transport inhibitor, 1-NPA. BMC Plant Biol. 13:76.

Tegg, R. S., Thangavel, T., Aminian, H., and Wilson, C. R. 2013b. Somaclonal selection in potato for resistance to common scab provides concurrent resistance to powdery scab. Plant Pathol. 62:922-931.

Thangavel, T., Tegg, R. S., and Wilson, C. R. 2014. Resistance to multiple tuber diseases expressed in somaclonal variants of the potato cultivar Russet Burbank. Sci. World J. 2014:Article ID 417697. doi:10.1155/2014/417697

Vaughn, S. F., and Lulai, E. C. 1991. The involvement of mechanical barriers in the resistance response of a field-resistant and a fieldsusceptible potato cultivar to Verticillium dahliae. Physiol. Mol. Plant Pathol. 38:455-465.

Waterer, D. 2002. Management of common scab of potato using planting and harvest dates. Can. J. Plant Sci. 82:185-189.

Wilson, C. R., Luckman, G. A., Tegg, R. S., Yuan, Z. Q., Wilson, A. J., Eyles, A., and Conner, A. J. 2009. Enhanced resistance to common scab of potato through somatic cell selection in cv. Iwa with the phytotoxin thaxtomin A. Plant Pathol. 58:137-144.

Wilson, C. R., Ransom, L. S., and Pemberton, B. M. 1999. The relative importance of seed-borne inoculum to common scab disease of potato and the efficacy of seed tuber and soil treatments for disease control. J. Phytopathol. 147:13-18.

Wilson, C. R., Tegg, R. S., Wilson, A. J., Luckman, G. A., Eyles, A., Yuan, Z. Q., Hingston, L. H., and Conner, A. J. 2010. Stable and extreme resistance to common scab of potato obtained through somatic cell selection. Phytopathology 100:460-467.

Zhao, Q., and Dixon, R. A. 2014. Altering the cell wall and its impact on plant disease: From forage to bioenergy. Annu. Rev. Phytopathol. 52:69-91. 